\title{
LIFETIME PREDICTION OF REINFORCED CONCRETE STRUCTURES IN CARBONATION ENVIRONMENTS CARBONATION MODELLING VS AIR PERMEABILITY MODELLING
}

\author{
Pedro FAUSTINO ${ }^{\text {, }}$ Fábio GONÇALVES ${ }^{\mathrm{b}}$, Ana BRÁS ${ }^{\mathrm{c}}$, Ângela NUNES ${ }^{\mathrm{d}}$ \\ ${ }^{a}$ Mouchel - Scotland Transerv, Glasgow, UK \\ ${ }^{b}$ Amey, - Consulting, Rail \& Strategic Highways, Birmingham, UK \\ ${ }^{c}$ Department of Architecture and Civil Engineering, University of Bath, UK \\ ${ }^{d}$ CDAC - SECIL, S.A. 2900-182 Setúbal, Portugal
}

Received 07 Jul 2014; accepted 11 May 2015

\begin{abstract}
This article compares two models for the prediction of lifetimes of reinforced concrete structures in carbonation environments based on different tests: carbonation test-based modelling and air permeability test-based modelling. The study also includes experimental testing of five concrete mixes with different types of cement in order to validate the models using safety factors. The tests included compressive strength, accelerated carbonation and air permeability. Both models are defined in a European standard as being alternative to each other, meaning that their results for the same concrete composition and the same environment should converge. The results show that both current models can scarcely constitute alternative to each other. Design lifetime results are far from similar for each concrete mix and each exposure class. The different nature of each test - accelerated carbonation and air permeability - and their different characteristic such as the scattering of results and the unrelated parameters of the modelling equations are some of the features discussed, including the possibility of using different safety factors as function of the model and definition of possible correlation between tests.
\end{abstract}

Keywords: air permeability, carbonation, corrosion, design lifetime, partial safety factor method, performance-based approach, semi-probabilistic method.

\section{Introduction}

There are currently several conceptual frameworks and prediction models for concrete structures exposed to carbonation and chloride contamination (DuraCrete 2000; Lay et al. 2003; BY 50 2004; CS TR 61 2004; Concrete Report 12 2007; Kamaitis 2008; Silva et al. 2014; Boutz et al. 2008; EHE 08 2008; Kwon et al. 2009; NIST 2011; Life-365 2012; Taffes, Sistonen 2013). However, the development of these models may present some difficulties such as the lack of information concerning the scattering of variables. Additionally, there is the difficulty in implementing some of these models along with time consuming procedure (Silva et al. 2014; Taffes, Sistonen 2013).

The Portuguese specification LNEC E465 (2009) has introduced a performance-based approach where a required performance is maintained throughout the intended life of the structure, along with the optimization of the lifetime costs (Narasimhan, Chew 2009). This approach is similar to those already in use in other European countries such as Finland (BY 50 2004), Sweden (Concrete Report 12 2007) and Spain (EHE 08 2008).
In the particular case of the performance-based Portuguese specification (LNEC E465 2009), which follows the philosophy of benchmark recommendations and standards (DuraCrete 2000; FIB bulletin 34 2006; ISO 16204 2012) a semi-probabilistic method is used where two different mathematical models:

1. Modelling equations based on $\mathrm{CO}_{2}$ diffusion tests through the concrete (LNEC E391 1993). The $1^{\text {st }}$ Fick's law is used assuming the $\mathrm{CO}_{2}$ flow as stationary. The carbonation depth is a function of time and the $\mathrm{CO}_{2}$ coefficient of diffusion;

2. Modelling equations based on air permeability tests in the concrete (LNEC E392 1993). This model represents the correlation between the values of the coefficient of air diffusion and the coefficient of air permeability in the concrete. In this case the carbonation depth is a function of time and the coefficient of air permeability of the concrete cover.

The first model has already been employed and analysed in the open literature for tested concrete composi-

Corresponding author: Pedro Faustino

E-mail:faustino3@gmail.com 
tions either for carbonation (Marques, Costa 2010; Neves et al. 2012b; Marques et al. 2013) or for chloride environments (Marques et al. 2012).

As regards the second model, based on air permeability tests, this article is the first presenting the comparison with the carbonation-based model based on the same experimental samples and this particular European specification. The correlation between the carbonation depth and air permeability has been assessed by different authors (Nilsson, Luping 1995; Neves et al. 2012a), which can give some contribution to the interpretation of the design lifetime results.

In order to assess the convergence between the two models defined by the Portuguese specification LNEC E465 (2009), which has not been done so far, this study quantifies the difference in the design lifetime estimates using both methods for carbonation induced corrosion.

\section{Corrosion of reinforcing steel in carbonation environments}

Corrosion of reinforcing steel depends directly on the environment surrounding the structures that is, relative humidity, $\mathrm{CO}_{2}$ concentration and wet /dry cycles (Verbeck 1958; Bakker 1988) The type and quality of materials chosen, compaction and curing of concrete during construction phase, that is porosity of concrete and quantity of matter that can be converted into carbonates is also a factor (Neves et al. 2012b).

Tuutti (1982) presented a model that considers the effect of deterioration by corrosion divided into two phases: the initiation phase (initiation period $t_{i}$ ), where the aggressive agent penetrates into the concrete until it reaches the reinforcing steel, in the case of $\mathrm{CO}_{2}$ diffusion, until the carbonation depth is equal to the thickness of the concrete cover; and the propagation phase (propagation pe$\operatorname{riod} t_{p}$ ), that begins with the onset of corrosion and where the duration depends on the limit established as regards a chosen criterion: cracking, delamination or steel section loss. The sum of both phases corresponds $t_{i}$ the lifetime of a structure $-t_{L}=t_{i}+t_{p}$.

European standard EN 206-1 (2000) and Eurocode 2 (EN 1992-1-1 2004) separate the environments in terms of the aggressive agents and both documents present exposure sub-classes for different microenvironments. In the case of carbonation induced corrosion, there are four classes:

- XC1 - concrete inside buildings with low air humidity or concrete permanently submerged in water;

- XC2 - concrete surfaces subject to long-term water contact. This includes many foundations;

- XC3 - concrete inside buildings with moderate or high air humidity or external concrete sheltered from rain;

- XC4 - concrete surfaces subjected to water contact or high humidity on a cyclic basis.

In this article exposure class XC1 is excluded due to its low level of aggressiveness.

\section{Reliability criteria for the design lifetime}

The performance-based approach and its relationship with the calculation of the design lifetime of reinforced concrete structures is based on reliability criteria established by Eurocode 0 (EN 1990 2002). In this code, three reliability classes are defined - RC1, RC2 and RC3 - relating to the importance of a certain structure/construction considered in terms of consequences due to failure. Each class is represented by a maximum probability of failure $P_{f}$ which takes into account the statistical scattering in action effects, the uncertainties in resistances and the uncertainties of the chosen model.

Despite the fact that the corrosion effect on reinforced concrete structures vary widely, as regards the consequence levels, the performance-based approach defined in LNEC E465 (2009) considers only the Serviceability Limit States: $P_{f}<11.5 \%(\mathrm{RC} 3) ; P_{f}<6.7 \%$ (RC2); $P_{f}<2.3 \%$ (RC3). The Eurocode 0 (EN 1990 2002) considers these limit states exclusively for the reliability class RC2 $\left(P_{f}<6.7 \%\right)$.

\section{Lifetime modelling}

This section describes the main features of the performance-based principles and the currently accepted deterioration model.

\subsection{Concrete cover}

The Eurocode 2 (EN 1992-1-1 2010) establishes the cover of reinforced concrete structural members and the dispersion of this variable in relation to its execution is also taken into account.

The nominal cover $c_{\text {nom }}(\mathrm{mm})$ and the minimum cover $c_{\text {min,dur }}(\mathrm{mm})$ are defined by this European code. The first is the value that should be considered in the construction project drawings and specifications:

$$
c_{\text {nom }}=c_{\text {min, dur }}+\Delta c_{d e v},
$$

where $\Delta c_{d e v}(\mathrm{~mm})$ is the expected deviation that depends on the quality control, which in the Portuguese case is the recommended value of $10 \mathrm{~mm}$.

According to FIB bulletin 34 (2006), the minimum concrete cover $c_{\text {min, dur }}$ may be interpreted as a $5 \%$ fractile characteristic value, where $\Delta c_{d e v}=1.645 \mathrm{~s}$, being $s$ the standard deviation of a concrete cover with a Gaussian distribution. Consequently, the standard deviation of the cover corresponds to $6 \mathrm{~mm}$.

The nominal cover $c_{\text {nom }}$ is assumed to represent the mean value. However, the minimum concrete cover $c_{\text {min,dur }}$ is the one used in the modelling equations of the partial safety factor method (Section 3.5).

\subsection{Initiation period $t_{i}$ based on accelerated carbonation tests}

The concept of carbonation resistance $R_{C 65}$ expressed by performance-based specification (LNEC E465 2009), corresponds to the ratio between the amount of $\mathrm{CO}_{2}$ 
necessary for complete carbonation of a concrete unit volume and the coefficient of diffusion through the concrete in equilibrium with an environment of $65 \%$ relative humidity $(\mathrm{RH})$ and a temperature of $20^{\circ} \mathrm{C}$.

The carbonation resistance $R_{C 65}$ (Eqn (2)) results from the laboratory results through an accelerated process with a concentration of $\mathrm{CO}_{2} C_{\text {accel }}$ of $90 \times 10^{-3} \mathrm{~kg} / \mathrm{m}^{3}$ (LNEC E391 1993). The duration of testing is $t_{1}$ and the subsequent carbonation depth $X_{1}$ :

$$
R_{C 65}=\frac{2 C_{\text {accel }} t_{1}}{X_{1}^{2}}=\frac{2 C_{\text {accel }}}{k_{a}^{2}} .
$$

The performance-based specification (LNEC E465 2009) includes the equation that expresses the $\mathrm{CO}_{2}$ diffusivity of hardened concrete throughout time - carbonation depth $x$, according to Eqn (3):

$$
x=\sqrt{\frac{2 \times \Delta C}{R_{C 65}}} t \sqrt{k_{0} k_{1} k_{2}}\left(\frac{t_{0}}{t}\right)^{n},
$$

where $\Delta C=0.7 \times 10^{-3} \mathrm{~kg} / \mathrm{m}^{3}$ is the difference of $\mathrm{CO}_{2}$ concentration between the exterior and the carbonation front, $k_{0}$ equals 3 and is a constant value that takes into account the testing method and conditions (LNEC E391 1993), $k_{1}$ considers the presence of relative humidity (LNEC E465 2009), $k_{2}$ quantifies the cure influence: 1.0 for normalized cure and 0.25 for a 3 day period of cure (LNEC E465 2009), $t_{0}$ is the reference period $=1$ year and $n$ is the parameter that quantifies the wet/dry cycle influence in time (LNEC E465 2009). Table 1 shows the values of parameters $k_{1}$ and $n$ for all exposure classes.

The initiation period $t_{i}$ is expressed as follows:

$$
t_{i}=\left[\frac{R_{C 65} c^{2}}{1.4 \times 10^{-3} k_{0} k_{1} k_{2} t_{0}^{2 n}}\right]^{\frac{1}{1-2 n}} .
$$

Table 1. Values of $k_{1}$ factor and $n$ factor

\begin{tabular}{c|c|c|c|c}
\hline & $\mathrm{XC} 1$ & $\mathrm{XC} 2$ & $\mathrm{XC} 3$ & $\mathrm{XC} 4$ \\
\hline$k_{1}$ & 1 & 0.2 & 0.77 & 0.41 \\
\hline$n$ & 0 & 0.183 & 0.02 & 0.085 \\
\hline
\end{tabular}

\subsection{Initiation period $t_{i}$ based on air permeability tests}

The model for the calculus of the initiation period $t_{i}$ based on air permeability tests is proposed as a direct alternative to that above (Section 3.2).

Following LNEC E465 (2009), this second model results from the fact that it has been experimentally observed that there is close relation between air diffusion and air permeability, where the pressure gradient is the driving force.

Following this principle, Eqn (5) was written to calculate the carbonation depth:

$$
x=\left(\frac{150^{2.5} t^{2.5 p} m . K T \times 10^{16}}{b^{1.25}} k_{2}\right)^{\frac{1}{2.5}},
$$

where $x$ is the carbonation depth (mm) at time $t$ (years), $m$ and $p$ are parameters that depend on the relative humidity of the concrete and consequently on the exposure class (Table 2). The parameter $b\left(\mathrm{~kg} / \mathrm{m}^{3}\right)$ is the calcium oxide of the hydrated cement matrix of the concrete that depends on the type of binder used and on the exposure class. The variable $K T$ is the coefficient of air permeability of the concrete cover in exposure humidity conditions and it depends on $m$ and therefore on the exposure class.

The equation in terms of $t_{i}$ is expressed as follows:

$$
t_{i}=\left(\frac{b^{1.25} \cdot c^{2.5}}{150^{2.5} m \cdot K T \times 10^{16}}\right)^{\frac{1}{2.5 p}},
$$

where $c$ is the concrete cover ( $\mathrm{mm}$ ), which corresponds to the limit of the carbonation depth immediately before the end of the initiation period.

Table 2. Values of $m^{*}, p$ and $b$ factor (LNEC E465 2009)

\begin{tabular}{c|c|c|c|c|c}
\hline \multirow{2}{*}{ RH (\%) } & \multirow{2}{*}{$m^{*}$} & \multirow{2}{*}{$p$} & \multicolumn{3}{|c}{$b\left(\mathrm{~kg} / \mathrm{m}^{3}\right)$} \\
\cline { 4 - 6 } & & & CEM I $^{* *}$ & $\mathrm{CEM} \mathrm{II} / \mathrm{B}$ & CEM IV \\
\hline 70 (XC3) & 0.725 & 0.48 & 460 & 350 & 230 \\
\hline 80 (XC4) & 0.347 & 0.42 & 485 & 360 & 240 \\
\hline 90 (XC2) & 0.159 & 0.33 & 535 & 410 & 265 \\
\hline
\end{tabular}

Notes: *tests were conducted on specimens in equilibrium with $\mathrm{RH}=65 \%$ instead of $\mathrm{RH}=60 \%$. The values of $m$ were changed proportionally.

**also applicable to CEM II/A-L.

\subsection{Propagation period $t_{p}$ - corrosion modelling}

The propagation period corresponds to the beginning of corrosion of steel reinforcement until a certain level of deterioration, which can result in crack formation due to steel increase of volume, delamination of concrete cover or rupture of steel bars due to loss of section.

The modelling of the propagation period is based on the quantification of the corrosion rate of steel reinforcement and the tension strength of concrete cover.

Table 3. Minimum propagation periods from corrosion start until cracking (LNEC E465 2009)

\begin{tabular}{c|c|c}
\hline Target life $t_{g}$ & $t_{g}=50$ years & $t_{g}=100$ years \\
\hline Exposure class & $t_{p}$ estimated (yrs) & $t_{p}$ estimated $(\mathrm{yrs})$ \\
\hline $\mathrm{XC1}$ & $>100$ & $>100$ \\
$\mathrm{XC} 2$ & 10 & 20 \\
$\mathrm{XC} 3$ & 45 & 90 \\
$\mathrm{XC} 4$ & dry region 15 & dry region 20 \\
& humid region 5 & humid region 10 \\
\hline
\end{tabular}

Specification LNEC E465 (2009) defines the minimum values of $t_{p}$, based on Faraday's law and empirical equations, that should be added to the design values of the initiation period $t_{i}$. Table 3 presents the minimum propagation periods for each exposure class and the target periods of 50 and 100 years. 


\subsection{Partial safety factor method}

For the modelling of the initiation period, the partial safety factor method defined by the performance-based specification LNEC E465 (2009) is carried out by a deterministic calculus where the probabilistic nature of the problem is taken into account using reduction factors (semi-probabilistic approach).

The implementation of the partial safety factor method starts with the definition of the values of each variable in the modelling equations (Eqns (4) and (6)) in either model: carbonation-based tests or air permeabilitybased tests.

Some of these variables consist of parameters defined by the specification (LNEC E465 2009) based on in-situ and laboratory tests and corresponding calibration. Except the concrete cover, all variables are quantified in the equations with their mean value. As explained above (Section 3.1), in view of the quality control of the execution of the reinforced concrete structures, the additional cover thickness may or may not be defined in the design stage.

In this specification (LNEC E465 2009) it is assumed that the additional $10 \mathrm{~mm}$ are required and should therefore be specified in the design stage. However, in both models, for the estimation of the initiation period the deterministic calculus considers the cover characteristic value, $\mathrm{c}_{\text {min, dur }}$ (Section 3.1).

The design lifetime $t_{L}$ is then calculated through the following equation:

$$
t_{L}=\frac{t_{i}}{\gamma}+t_{p}
$$

where $t_{i}$ is the initiation period (obtained from Eqns (4) and (6), depending on the model), $\gamma$ is the safety factor according to LNEC E465 (2009) - 2.0 (RC1), 2.3 (RC2) or $2.8(\mathrm{RC} 3)$ and $t_{p}$ is the propagation period given in Table 3 considering the crack formation as the limiting criterion.

In the present study, the determination of the design lifetime $t_{L}$ using the performance-based approach is carried out considering the reliability class RC3 (failure probability $\leq 2 \%$ ) for the exposure classes XC2, XC3 and
$\mathrm{XC} 4$. The concrete cover value was chosen to following the limits of the prescriptive specification (LNEC E464 2009) for a 50 year target life $t_{g}$.

\section{Experimental program}

Even though the present study deals with the performance-based method for the estimate of the design lifetime $t_{L}$, the definition of the concrete mixes was defined having a prescriptive specification (LNEC E464 2009) as reference.

The performance of these compositions was analysed regarding the testing results, as to compressive strength (EN 12390-3 2003) - performed at CDAC - and as to accelerated carbonation depth (LNEC E391 1993) and air permeability (LNEC E392 1993) - performed at ESTB - Polytechnic Institute of Setúbal.

\subsection{Concrete mixes}

Considering the exposure classes XC2, XC3 and XC4, the concrete mixes were made in order to respect the limits of the specification LNEC E464 (2009) with respect to water/cement ratio, cement dosage, and cement type.

For each concrete mix the used cements comply with the European standard EN 197-1 (2000). Table 4 shows the cement types and corresponding specific surface (Blaine test), whereas Table 5 presents the constituents of each composition designated according to the cement type.

\subsection{Tests procedures and results}

Prior to the planned tests, the specimens of all concrete mixes were subjected to specific conditioning in accordance with related standards and laboratory procedures.

For the compressive strength tests, samples were subjected to wet curing of $100 \%$ of relative humidity (RH) until the age of 28 days.

With regard to accelerated carbonation tests, the conditioning comprised a wet curing $(\mathrm{RH}=100 \%$ at $20 \pm 2{ }^{\circ} \mathrm{C}$ ) of 14 days after the mixing of the specimens followed by a period of 14 days of dry curing in an environment of $50 \pm 5 \%$ of relative humidity and $20 \pm 2{ }^{\circ} \mathrm{C}$. At

Table 4. Cements and properties

\begin{tabular}{l|c|c|c|c|c}
\hline Cement type & Constituents & Ignition loss & Insoluble Residue & $\begin{array}{c}\text { Blaine } \\
\left(\mathrm{cm}^{2} / \mathrm{g}\right)\end{array}$ & $\begin{array}{c}\text { Comp. strength } \\
28 \mathrm{~d}(\mathrm{MPa})\end{array}$ \\
\hline $\begin{array}{l}\text { CEM I } \\
52,5 \mathrm{R}\end{array}$ & $>95 \% \mathrm{~K}$ & $2.2 \%$ & $1.5 \%$ & 4777 & 61.9 \\
\hline CEM I & $>95 \% \mathrm{~K}$ & $3.0 \%$ & $0.7 \%$ & 3900 & 58.6 \\
$42,5 \mathrm{R}$ & & & & \\
\hline CEM II/A-L & $\begin{array}{c}>89 \% \mathrm{~K} \\
6 \% \mathrm{LF}\end{array}$ & $8.1 \%$ & $1.4 \%$ & 3946 & 53.3 \\
$42,5 \mathrm{R}$ & $\begin{array}{l}>73 \% \mathrm{~K} \\
\text { CEM II/B-L }\end{array}$ & $12.8 \%$ & $2.4 \%$ & 4152 & 39.7 \\
$32,5 \mathrm{~N}$ & $22 \% \mathrm{LF}$ & & & & \\
\hline CEM IV/A & $>69 \% \mathrm{~K}$ & $2.3 \%$ & $26.3 \%$ & 4292 & 44.3 \\
$\mathrm{~V} \mathrm{32,5 \textrm {R }}$ & $26 \% \mathrm{FA}$ & & & & \\
\hline
\end{tabular}

Note: $\mathrm{K}$ - clinker; LF - limestone filler; FA - fly ash. 
Table 5. Composition of the concrete mixes

\begin{tabular}{l|c|c|c|c|c|c}
\hline \multicolumn{1}{c|}{ Concrete mix } & Cement dosage & $\begin{array}{c}\text { Sand } \\
0.25-0.5\end{array}$ & $\begin{array}{c}\text { Sand } \\
0.5-1.0\end{array}$ & $\begin{array}{c}\text { Gravel } \\
8-12\end{array}$ & water & w/c \\
\hline CEM I 52.5R & 320 & 205 & 657 & 780 & 170 & 0.53 \\
\hline CEM I 42.5R & 320 & 205 & 657 & 780 & 170 & 0.53 \\
\hline $\begin{array}{l}\text { CEM II/A-L } \\
\text { 42.5R }\end{array}$ & 320 & 205 & 657 & 780 & 170 & 0.53 \\
\hline $\begin{array}{l}\text { CEM II/B-L } \\
\text { 32.5N }\end{array}$ & 320 & 210 & 671 & 796 & 154 & 0.48 \\
\hline $\begin{array}{l}\text { CEM IV/A-V } \\
\text { 32.5R }\end{array}$ & 320 & 210 & 671 & 796 & 154 & 0.48 \\
\hline
\end{tabular}

the age 28 days all the specimens were introduced in the carbonation chamber.

In the case of the air permeability tests, the conditioning of the specimens included as well a wet curing period of 14 days at $100 \% \mathrm{RH}$ and $20 \pm 2{ }^{\circ} \mathrm{C}$ and the following 14 days at $65 \pm 5 \% \mathrm{RH}$ and $20 \pm 2{ }^{\circ} \mathrm{C}$.

For each concrete mix 18 specimens were produced for the three tests that were previously planned.

\subsubsection{Compressive strength}

The specimens used for the compressive strength tests were cubes with $150 \mathrm{~mm}$ side length and the test itself was carried out according to the definitions of EN 12390-3 (2003).

\subsubsection{Accelerated carbonation}

In this case the concrete specimens were discs with $100 \mathrm{~mm}$ diameter and $50 \mathrm{~mm}$ of thickness following the criteria of LNEC E391 (1993).

After the 28 days of conditioning, all the specimens were placed in the carbonation chamber at $20{ }^{\circ} \mathrm{C}$ and $65 \% \mathrm{RH}$ and a $\mathrm{CO}_{2}$ concentration of $5 \%$. For each concrete mix there were four sets of specimens so that each set could be tested at different ages. Accordingly, the four sets of specimens were removed from the chamber 7, 14, 28 and 43 days after being subjected to accelerated carbonation and then broken in two halves and tested with a solution of $0.5 \%$ of phenolphthalein in alcohol (Fig. 1).

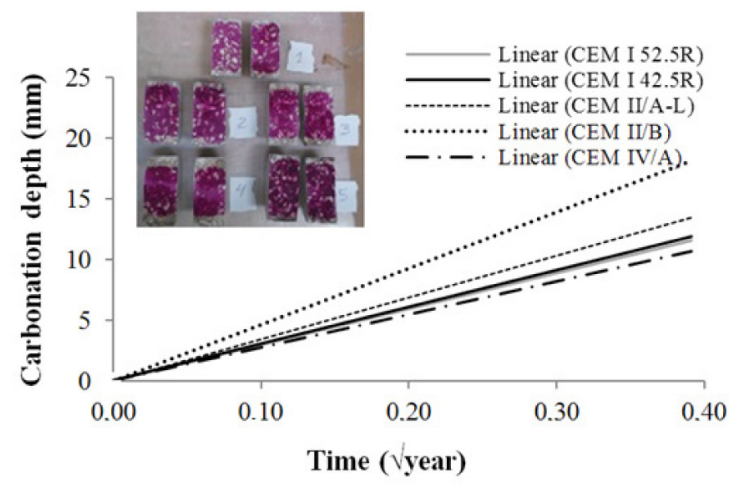

Fig. 1. Results of the accelerated carbonation tests

\subsubsection{Air permeability}

The specimens prepared for the air permeability tests (Fig. 2) were concrete discs with $150 \mathrm{~mm}$ diameter and $50 \mathrm{~mm}$ of thickness following the criteria of LNEC E392 (1993) using the Torrent Permeability Tester (PROCEQ).

\subsubsection{Tests results}

The results of the tests are presented in Figures 2 and 4 and Table 6 with mean values and corresponding coefficients of variation.

As regards the accelerated carbonation tests the results are presented in terms of the coefficient of carbonation $k_{a}$ (slope of carbonation depth vs square of time in

Table 6. Concrete experimental characterization. Tests results at the age of 28 days - mean values (coefficient of variation $-\mathrm{CoV}$ for $R_{C 65}$ and $K T$ )

\begin{tabular}{|c|c|c|c|c|}
\hline Concrete mix & $\begin{array}{c}f_{c} \\
(\mathrm{MPa})\end{array}$ & $\begin{array}{c}k_{a} \\
(\mathrm{~mm} / \sqrt{ } \mathrm{yr})\end{array}$ & $\begin{array}{c}R_{C 65} \\
\left(\mathrm{~kg} \mathrm{yr} / \mathrm{m}^{5}\right)\end{array}$ & $\begin{array}{c}K T \\
\left(10^{-16} \mathrm{~m}^{2}\right)\end{array}$ \\
\hline CEM I 52.5R & 62,1 & 29.5 & $207(17 \%)$ & $0,123(29 \%)$ \\
\hline CEM I 42.5R & 56,1 & 32.1 & $175(18 \%)$ & $0,075(22 \%)$ \\
\hline CEM II/A-L 42.5R & 47,5 & 33.3 & $162(14 \%)$ & $0,130(32 \%)$ \\
\hline CEM II/B-L $32.5 \mathrm{~N}$ & 41,1 & 46.2 & $85(9 \%)$ & $0,210(20 \%)$ \\
\hline CEM IV/A-V 32.5R & 62,3 & 25.6 & $274(16 \%)$ & $0,081(35 \%)$ \\
\hline
\end{tabular}

Note: $f_{c}$ - compressive strength (CoV varied between $2 \%$ and $\left.5 \%\right) ; k_{a}$ - carbonation coefficient;

$R_{C 65}$ - carbonation resistance; $K T$ - coefficient of air permeability. 


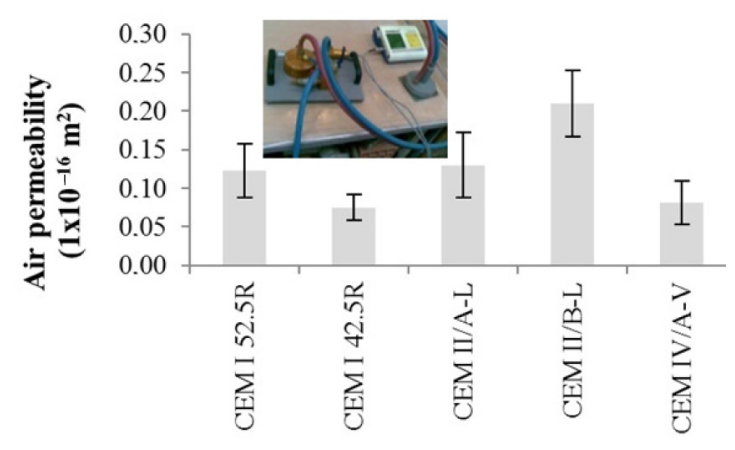

Fig. 2. Results of the air permeability tests

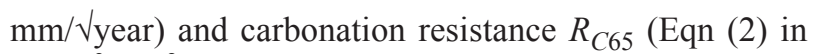
$\left[\mathrm{kg} / \mathrm{m}^{3}\right] /\left[\mathrm{m}^{2} /\right.$ year $\left.]\right)$.

As for the air permeability tests the results are presented in terms of the coefficient of air permeability $K T$.

\section{Design lifetime results and discussion}

In order to respect the fundamentals of the exposure classes XC2, XC3 and XC4 for a target period of 50 years, a minimum concrete cover $c_{\text {min,dur }}$ of $25 \mathrm{~mm}$ is used for classes XC2 and XC3 while for class XC4 the value used is of $30 \mathrm{~mm}$. The chosen reliability class is RC3, which means a maximum probability of failure of $2.3 \%$. All concrete mixes were defined accordingly (Table 5).

In the present analysis, in addition to the inherent conditions of the specific exposure classes, a normalized cure of the reinforced concrete elements is considered and the propagation period is defined as a fixed value following the premises of the performance-based specification (LNEC E465 2009).

\subsection{Accelerated carbonation modelling vs Air permeability modelling}

The modelling results of the design lifetime $t_{L}$, alongside with the initiation and propagation periods $-t_{i}$ and $t_{p}-$ are presented in the graphs of Figures 3,4 and 5. The modelling results are shown in years for the mathematical model that is based on the equations and tests regarding

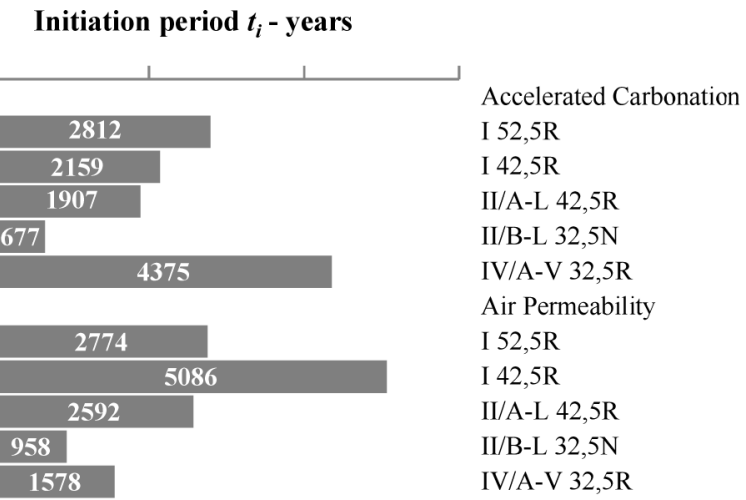

Fig. 3. Design lifetime for target period of 50 years, by accelerated carbonation and air permeability methods, for the exposure class XC2 the accelerated carbonation and the five concrete mixes with different types of cement - upper half - and in the lower half of each graph the results concerning the modelling equations based on air permeability tests.

Being the purpose of the present study the comparison of two methods that constitute an alternative to one another, as can be seen from Figures 3 to 5, it seems variable the convergence of results as regards the design lifetime results $t_{L}$, especially if the exposure classes XC2 and $\mathrm{XC} 4$ are considered.

As regards the exposure class $\mathrm{XC} 3$, the modelling results of the design lifetime $t_{L}$ of both models are closer between each other. However, in this class, if the results of the initiation period $t_{i}$ are analysed it is evident that there is an equivalent trend in relation to the exposure classes XC2 and XC4. The reason for this has to do with the fact that for class $\mathrm{XC} 3$ the propagation period $t_{p}$, whose modelling or definition does not depend on the accelerated carbonation and air permeability tests, has a higher proportion of the entire calculated lifetime. Comparatively, for classes XC2 and XC4 the contribution of $t_{p}$ is almost negligible for $t_{L}$.

Subsequently, the question of the irregular convergence is also observed for class $\mathrm{XC} 3$, considering the

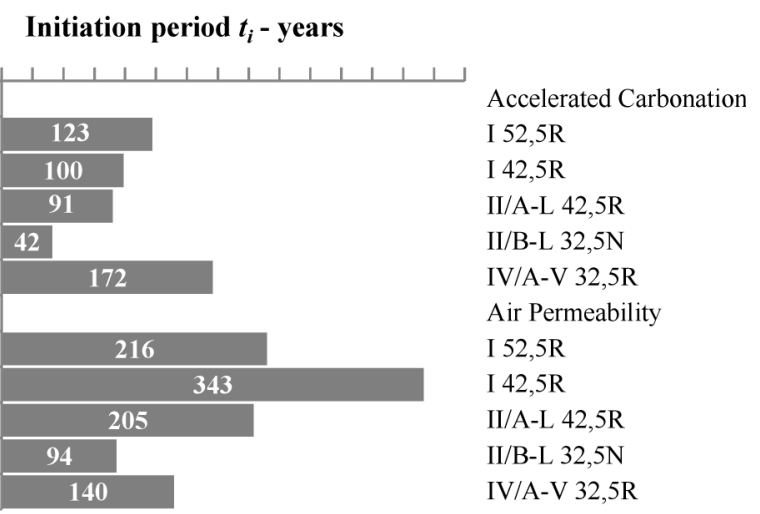

Fig. 4. Design lifetime for target period of 50 years, by accelerated carbonation and air permeability methods, for the exposure class $\mathrm{XC} 3$

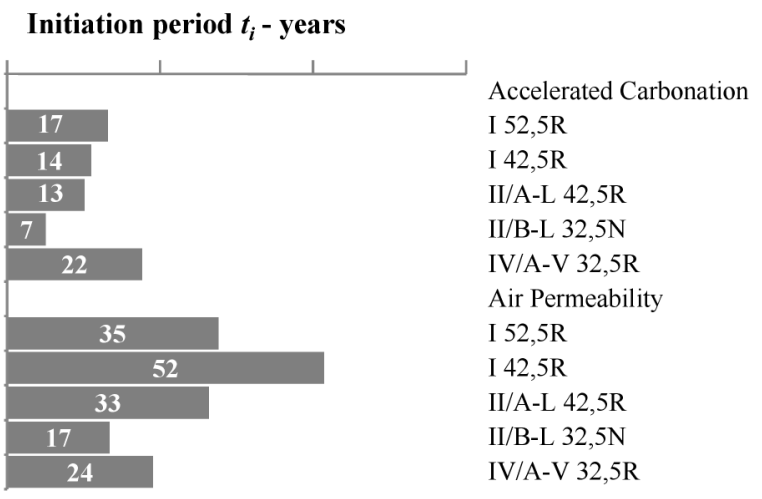

Fig. 5. Design lifetime for target period of 50 years, by accelerated carbonation and air permeability methods, for the exposure class XC4 - humid region 


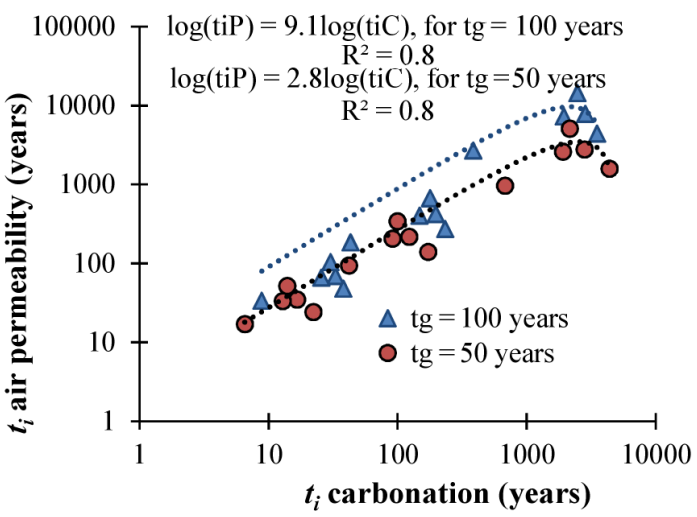

Fig. 6. Results of initiation period according to accelerated carbonation tests $(x-x)$ and air permeability tests $(y-y)$ for $\mathrm{XC} 2, \mathrm{XC} 3$ and $\mathrm{XC} 4$, for $t_{g}=50$ and 100 years

results of the initiation period, where the influence of the tests and equations of each model takes part.

In order to quantify the difference between both models, Figure 6 presents the initiation period according to accelerated carbonation tests $(x-x)$ and air permeability tests $(y-y)$ for $t_{g}=50$ and 100 years. Results show that there is a logarithmic correlation between $t_{i C}$ and $t_{i P}$ using those two different tests. It is shown that the logarithmic value of $t_{i P}$ is almost 3 times the logarithmic of $t_{i C}$ for a target period of 50 years and 9 times if the target period is about 100 years. Figures 3 to 5 help in finding possible convergence. As referred before, due to the relevant influence of $t_{p}$, the ratio for the design lifetime in class XC3 presents values that may be considered not far from 1.0 (perfect match) (Fig. 4), varying from 0.74 to 0.97 , the exception is the concrete mix CEM I 42.5R with $t_{L C}$ $t_{L P}=0.61$. Nonetheless, the ratio $t_{i C} t_{i P}$, which relates to the initiation period, presents values far from 1.0 varying from 0.27 to 0.48 . As an exception, concrete mix CEM IV/A presents ratios $t_{i C} / t_{i P}$ between 0.93 and 0.97 . For class XC2 the ratios vary from 0.71 to 1.01 which correspond to a relatively fair convergence, except for concrete mix CEM IV/A where the ratio is of 2.77. In the case of class XC4 only CEM IV/A show a ratio not far from 1.0 (1.23) while the remaining mixes present ratio values between 0.29 and 0.57 which reveals a significant distance between both models.

Taking into account the two parts of the presented study - i) the experimental work and ii) the calculus and analysis of the design lifetime - it is reasonable to state that according to both sets of results, those of laboratory tests and the ones of the modelling calculus, the two mathematical models do not provide similar results in most cases. The results presented in Figure 6 show that there is a logarithmic correlation between $t_{i C}$ and $t_{i P}$. However, these results do not mean that there is a convergence between both test methods, but can help in the estimation for initiation period.

At this stage, it is possible to discuss which might be the main causes of such a differences between some of the results of both models.
Primarily, it should be borne in mind that the principle that supports the definition of the safety factor value $\gamma$ defined by LNEC E465 (2009) relies on lifetime having a lognormal distribution with a CoV of 0.5 (RILEM Report 14 1996). Additionally, these safety factors do not consider any uncertainty related to each of the modelling equations of the initiation period.

Furthermore, three main topics should be regarded as highly influencing the difference between both models:

1. Different equations and consequently possibly different uncertainty levels;

2. Different tests - the nature of the carbonation test involves both physical and chemical processes, while the air permeability test is of physical nature;

3 . The scattering of results of the air permeability test is approximately the double of those of the accelerated carbonated tests (Table 5).

Being these three aspects the plausible origin for the differences between the studied models, the one that stands out is topic 3 since it is more tangible in terms of results. In fact, even though the experimental results of the present work may not be sufficient to be representative of such a difference concerning the dispersion of tests results, previous research studies have observed similar problem (Nilsson, Luping 1995; Neves et al. 2012a).

Bearing in mind that none of the models can be considered as "more accurate" than the other, in order to analyse to what extent the dispersion of test results is actually affecting the convergence between both models, it is relevant to carry out an analysis in which all the statistical parameters of the experimental data are considered.

\subsection{Analysis of the performance of each concrete mix}

The decision of calculating the design lifetime for the exposure classes $\mathrm{XC} 2, \mathrm{XC} 3$ and $\mathrm{XC} 4$ and the chosen five concrete mixes was driven by the simplicity with which the overall analysis can be done. Some results may, yet, be considered "unrealistic", since it seems inaccurate to conclude that any reinforced concrete structure, without significant retrofitting intervention, will last more than 100-120 years.

With regards to the carbonation modelling, the relative performance of the five concrete mixes is similar either test or lifetime results are evaluated. The reason for this has to do with the chemical nature of the test in which the reaction of $\mathrm{CO}_{2}$ with the hydroxides of the cement paste is assessed.

The analysis of carbonation resistance $R_{C 65}$ in Table 6 and the lifetime results in Figures 3 to 5 show that, amongst all mixes, concrete mix CEM IV/A has the best performance while on the opposite side CEM II/B has the lowest results. For CEM IV/A such results may be explained by the combined effect of lower w/c and a more refined porous structure due to the blend of fly ash with clinker, which sustained by the air permeability test result (one of the lowest values.

As to the air permeability modelling, for the performance of the different concrete mixes the direct analysis 
of the air permeability tests (Table 6) does not have a direct relation with lifetime modelling results (Figs 3 to 5). Since the test deals uniquely with the air diffusion through the porous structure of the specimens, the model presented by LNEC E465 (2009) includes parameter $b$ that takes into account the type of binder used in a concrete composition. Consequently, concrete mix CEM IV/A shows a lifetime value behind concrete mixes CEM I 52.5R, CEM I 42.5R and CEM II/A, despite the first having one of the lowest test results of air permeability. As regards concrete mix CEM I 42.5R, its outstanding performance compared to the other compositions is evident. With an air permeability coefficient similar to that of concrete mix blended with fly ash $-K T\left(\right.$ CEM I 42.5) $=0.075 \times 10^{-16} \mathrm{~m}^{2}$ and $K T(\mathrm{CEM} \mathrm{IV} / \mathrm{A})=0.081 \times 10^{-16} \mathrm{~m}^{2}-$ the design lifetime result for concrete mix CEM I 42.5R is, however, substantially higher given the fact that the parameter $b$ considered is also higher (Table 6).

\section{Conclusions}

The two studied models are based on accelerated carbonation and air permeability tests and were defined to be an alternative to each other using a semi-probabilistic approach, meaning that the design lifetime calculated using both models should have fair similarity.

The modelling results show that globally there is no "reasonable" convergence between both methods which, as discussed above, might be related to the nature of the tests, the different scattering level and the consideration of these combined effects in the adopted safety factors, which are defined with the same value in both models. The results presented in Figure 6 show that there is a logarithmic correlation between $t_{i C}$ and $t_{i P}$ (not a convergence between both values) that can help in the estimation of initiation period.

As regards the prediction of lifetime in environments where is the aggressive agent, given the prevailing option by recommendations and standards of using the models based on accelerated carbonation, there may be the tendency to consider these models as the reference or the "correct" ones. Analysing the results of both models it may be tempting to conclude that it should be the model based on air permeability tests that should meet the results of the one based on carbonation tests. It would not be precipitant, though, to reflect otherwise.

The results of this study show the importance of future discussion for the improvement of the convergence between carbonation test-based and air permeability testbased models, with respect to carbonation induced corrosion.

\section{References}

Bakker, R. F. M. 1988. Initiation period, in P. Schiessl (Ed.). Corrosion of steel in concrete. New York: RILEM/Chapmann and Hall.

Boutz, M.; van der Wegen, G.; Roelfstra, P.; Haverkort, R. 2008. Service life design of concrete structures by numerical modelling of chloride ingress, in Proceedings of International RILEM Symposium on Concrete Modelling - ConMod'08, 2008, Delft, The Netherlands. RILEM Publications, 307-315.

BY 50. 2004. Concrete standard. Finland Concrete Information, Finland. 214 p.

Concrete Report 12. 2007. Guidance for the life of the design of concrete structures. Swedish Concrete Association, Sweden. $141 \mathrm{p}$.

Concrete Society Technical Report 61 (CS TR 61). 2004. Enhancing reinforced concrete durability. Camberley: The Concrete Society. 207 p.

DuraCrete. 2000. Probabilistic performance based durability design of concrete structures. The European Union - Brite EuRam III. DuraCrete. Final Document BE95-1347/R17. CUR. Gouda. Netherlands.

EHE 08. Anejo 9 - Consideraciones adicionales sobre durabilidade. El Real Decreto 1247/2008 (in Portuguese).

EN 12390-3. Testing hardened concrete - Part 3: Compressive strength test. Brussels: CEN, 2003. 22 p.

EN 197-1. Cement - Part 1: Composition, specifications and conformity criteria for common cements. Brussels: CEN, 2000. 34 p.

EN 1990. Eurocode 0. Bases of structural design. Brussels: CEN, 2002. 119 p.

EN 1992-1-1. Eurocode 2. Design of concrete structures. Part 1-1: General rules and rules for buildings. Brussels: CEN, 2004. 225 p.

EN 206-1. Concrete - Part 1: specification, performance, production and conformity. Brussels: CEN, 2000. 74 p.

FIB Bulletin 34. 2006. Model code for service life design. Lausanne, Switzerland.

ISO 16204. Durability - Service life design of concrete structures. Geneva: International Organization for Standardization, $2012.31 \mathrm{p}$.

Kamaitis, Z. 2008. Modelling of corrosion protection for reinforced concrete structures with surface coatings, Journal of Civil Engineering and Management 14(4): 241-249. http://dx.doi.org/10.3846/1392-3730.2008.14.23

Kwon, S. J.; Na, J. U.; Park, S. S.; Jung, H. S. 2009. Service life prediction of concrete wharves with early-aged crack: Probabilistic approach for chloride diffusion, Structural Safety 31(1): 75-83.

http://dx.doi.org/ 10.1016/j.strusafe.2008.03.004

Lay, S.; Schieß1, P.; Cairns, J. 2003. Service life models: Instructions on methodology and application of models for the prediction of the residual service life for classified environmental loads and types of structures in Europe. LIFECON project [online], [cited 10 May 2015]. Available from Internet: http://lifecon.vtt.fi/d32.pdf

Life-365. 2012. Life-365 software overview [online], [cited 10 May 2015]. Available from Internet: http://www.life-365.org/overview.html

LNEC E391. Concrete. Determination of carbonation resistance. Lisbon: LNEC, 1993 (in Portuguese).

LNEC E392. Concrete. Determination of air permeability. Lisbon: LNEC, 1993 (in Portuguese).

LNEC E464. Concrete. Prescriptive methodology for a design working life of 50 and 100 years. Lisbon: LNEC, 2009 (in Portuguese).

LNEC E465. Concrete. Methodology for estimating the concrete performance properties allowing to comply with the design working life of the reinforced or pre-stressed concrete structures under environmental exposures XC and XS. Lisbon: LNEC, 2009 (in Portuguese).

Marques, P. F.; Chastre, C.; Nunes, A. 2013. Carbonation service life of RC for concrete with Portland and blended cements, Cement and Concrete Composites 37: 171-184. http://dx.doi.org/10.1016/j.cemconcomp.2012.10.007 
Marques, P. F.; Costa, A. 2010. Service life of RC structures: carbonation induced corrosion. Prescriptive vs performance-based methodologies, Construction and Building Materials 24(3): 258-265. http://dx.doi.org/10.1016/j.conbuildmat.2009.08.039

Marques, P. F.; Costa, A.; Lanata, F. 2012. Service life of RC structures: chloride induced corrosion. Prescriptive vs performance-based methodologies, Materials and Structures 45: 277-296. http://dx.doi.org/10.1617/s11527-011-9765-2

Narasimhan, H.; Chew, M. Y. L. 2009. Integration of durability with structural design: an optimal life cycle cost based design procedure for reinforced concrete structures, Construction and Building Materials 23(2): 918-929. http://dx.doi.org/10.1016/j.conbuildmat.2008.04.016

Neves, R.; Branco, F.; de Brito, J. 2012a. About the statistical interpretation of air permeability assessment results, $\mathrm{Ma}$ terials and Structures 45: 529-539. http://dx.doi.org/10.1617/s11527-011-9780-3

Neves, R.; Branco, F.; de Brito, J. 2012b. A method for the use of accelerated carbonation tests in durability design, Construction and Building Materials 36: 585-591. http://dx.doi.org/10.1016/j.conbuildmat.2012.06.028
Nilsson, L.; Luping, T. 1995. Relations between different transport parameters, in H. Hilsdorf, J. Kropp (Eds.). Performance criteria for concrete durability. London: E\&FN Spon Press, 15-32.

NIST. 2011. 4sight: concrete service life prediction [online], [cited 10 May 2015]. Available from Internet: http://concrete.nist.gov/4sight/

RILEM Report 14. 1996. Durability design of concrete structures. London: E\&FN Spon Press. 270 p.

Silva, A.; Neves, R.; de Brito, J. 2014. Statistical modelling of carbonation in reinforced concrete, Cement and Concrete Composites 50: 73-81. http://dx.doi.org/10.1016/j.cemconcomp.2013.12.001

Taffes, W. Z. J.; Sistonen, E. 2013. Service life prediction of repaired structures using concrete recasting method: stateof-the-art, Procedia Engineering 57: 1138-1144. http://dx.doi.org/10.1016/j.proeng.2013.04.143

Tuutti, K. 1982. Corrosion of steel in concrete. CBI Research Report no 4.82. Swedish Cement and Concrete Research Institute (CBI), Stockholm. 468 p.

Verbeck, G. 1958. Carbonation of hydrated Portland cement. PCA Bulletin 87. Portland Cement Association, Illinois, USA, 17-36.

Pedro FAUSTINO. MSc, Structural Engineer at LEB, Ltd. in Portugal. He received his degree in Civil Engineering at NOVA Lisbon University in 2002 and his MSc degree at IST - Technical University of Lisbon in 2007. He has carried out projects for the durability retrofitting and repair and strengthening of reinforced concrete structures. He has also conducted research studies as regards durability and strengthening of reinforced concrete structures. He has authored and co-authored approximately 20 publications concerning his developed research studies.

Fábio GONÇALVES. MSc in Civil Engineering received at the ESTB-Polytechnic Institute of Setúbal (IPS) in Portugal in 2013. He has co-authored research projects in the field of durability of reinforced concrete structures and the thermal performance of buildings using systems with cork and industry waste.

Ana BRÁS. PhD, Civil Eng, Adjunct Professor at the ESTB-Polytechnic Institute of Setúbal (IPS) in Portugal. She received her $\mathrm{PhD}$ degree at the NOVA Lisbon University in 2009. She authored and co-authored approximately 20 research publications and has reviewed articles for ISI journals. Her research interest includes buildings life cycle analysis, buildings thermal performance, fresh and hardened state performance of concrete with blended cements, concrete and mortars blended with industry waste.

Ângela NUNES. MSc in Materials Engineering. Executive Director at SECIL S.A. in CDAC - Cement Application Development Centre. She received her degree in Civil Engineering at IST - Technical University of Lisbon in 1984 and her MSc degree by joint universities of NOVA/IST/FEUP in 1996. She has given technical support for cement applications for designers and architects in special projects with white, coloured and textures concrete. Conducts cement/concrete performance control and quality specification, market oriented for Secil cement plants in 3 continents. Manages the Secil concrete Laboratory for concrete, aggregates and precast tests. Representative of Secil corporate member at RILEM. Manages Secil's product development plan for cement, concrete mortars and precast products for the delivery of new market oriented new cementitious-based products. 